\title{
Not a "Real" Period?: Social and Material Constructions of Menstruation
}

\author{
Katie Ann Hasson
}

\begin{abstract}
Menstruation, as a "natural" bodily process, seems self-evident; this allows it to work as an enduring and central marker of difference in essentialist conceptions of sex and gender. ${ }^{l}$ Considered to be a nearly universal female experience, ${ }^{2}$ it functions as a literal and symbolic marker of sex and sexuality, fertility, age, and health. Challenging essentialism, feminist scholarship has analyzed the varying social construction of menstruation in different places and times (Bobel 2010; Buckley and Gottlieb 1988; Delaney, Lupton, and Toth 1988; Fingerson 2006; Freidenfelds 2009; Lee and Sasser-Coen 1996; Martin [1987] 2001). This research has focused most often on representations and individual experiences of menstruation, mirroring the analytic split between sex as biological and gender as cultural and social, which often leaves the biological outside the range of feminists' critical examination (Fausto-Sterling 2005; Roberts 2007). The cultural and scientific categories with which we categorize and study menstruation are important to how we understand, experience, and intervene in it. Drawing on analyses of the material aspects of hormones and the menstrual cycle, recent feminist scholarship has brought necessary attention to the ways biology interacts with and is dynamically shaped by social and cultural environments (Fausto-Sterling 2000; Roberts 2007). Overall, feminist scholars have paid more attention to the cultural meanings and norms that govern menstruation than to what menstruation is or how it is defined. In doing so, what counts as menstruation
\end{abstract}


is taken for granted, and the complex choreography that can alternately shift or stabilize definitions of menstruation is overlooked.

Despite seeming self-evident, menstruation is not always easily defined. When technologies alter whether or when menstruation occurs, they often raise definitional questions, and menstruation's close links to reproduction raise the stakes. We can see this, for example, when asking whether medications to "bring on blocked menses" act on menstruation or pregnancy. Scholars have questioned whether the bleeding produced by these medications should be considered menstruation, miscarriage, or abortion (Luker 1984; van de Walle and Renne 2001). It took significant, coordinated effort by nineteenth-century physicians and politicians in the United States to shift the understanding of their use; what had been generally accepted as the restoration of healthy menstruation was redefined as illegal abortion (Luker 1984; Reagan 1997). Similarly, the feminist self-help health technique of "menstrual extraction,"3 developed by U.S. women's health activists in the 1970s, purposely occupied an ambiguous position between regulating menstruation and regulating reproduction (Mamo and Fosket 2009; Murphy 2012). Historical cases like these provide examples of how definitions of menstruation have been negotiated and institutionalized in conjunction with technologies that materially alter bleeding.

Although it is rarely discussed in this way, hormonal birth control is a prime site for the elision of regulating reproduction and regulating menstruation. When oral contraceptives were first approved by the Food and Drug Administration (FDA) and introduced in the United States, they benefited from the ambiguity of the effects exogenous hormones have on bleeding and conception. Enovid, the first hormonal birth control pill, was FDA approved in 1957 not as a contraceptive but rather as a medication for treating menstrual symptoms; it was accompanied by a warning that it had the side effect of stopping ovulation (Watkins 1998). As a treatment for menstrual symptoms, Enovid could pass through FDA scrutiny and enter the market, sidestepping (some) moral debates on birth control while maintaining the possibility of its off-label use as contraception. It was not until 1960 that Enovid's producer requested and received FDA approval for its use as a contraceptive (Junod and Marks 2002; Watkins 1998). The initial developers of the birth control pill knew that the hormones in the pill suppressed both ovulation and menstruation (Marks 2001). To emphasize the "naturalness" of the pill and increase its acceptability (to users, pharmaceutical executives, and religious officials), they designed a regimen with a pill-free break that produced bleeding similar to a menstrual period (Marks 2001; Watkins 1998). Menstrual suppression was thus always a possible use for the pill, but deliberate decisions by developers obscured these effects on bleeding.

The introduction of menstrual suppression birth control pills-oral contraceptives such as Seasonale, Seasonique, and Lybrel, which are taken in an extended regimen to produce fewer periods per year-made the ways that oral contraceptives regulate bleeding highly visible. Menstrual suppression 
birth control pills are nearly identical to existing hormonal birth control, changing only the regimen of how many pills with active hormones are taken before a "break" from hormones that allows bleeding to occur (Watkins 2012). This change incorporates previously known but little-mentioned ways that all hormonal birth control changes bleeding and widely practiced but "unofficial" or "off-label" uses, recreating oral contraceptives as menstrual suppression in the process. Available since 2003 in the United States, menstrual suppression birth control has attracted a great deal of attention; however, the focus on suppressing menstruation as a novel feature of birth control has precluded attention to both the continuities present in regulating menstruation and the way menstrual suppression includes a redefinition of menstruation itself. To make birth control into "menstrual suppression," monthly bleeding-once relied on to emphasize the naturalness of hormonal birth control-has been redefined as a side effect with no relation to "natural" menstruation. How were these understandings and definitions of menstruation changed following the introduction of menstrual suppression birth control? What are the implications of these changes for gendered embodiment?

The redefinition of menstruation, including how it is understood in relation to birth control hormones, is central to understanding menstrual suppression birth control and its effects on gendered embodiment. I argue that, following the introduction of menstrual suppression, menstruation itself was redefined, proliferating new categories of bleeding across clinical, regulatory, and popular discourse. New definitions and terminology for menstruation explicitly aimed to change women's understandings of menstruation and normalize menstrual suppression. The case of menstrual suppression birth control pills provides an opportunity to study the work of redefining a biological process understood as quintessentially natural and deeply significant for gendered embodiment. Further, this case provides a challenge to gender scholarship to consider both the social and material construction of gendered bodies. What material aspects of menstruation-what interactions of bodies and hormones, what timing and sources of bleeding - are drawn on to define and redefine menstruation and menstrual suppression?

In what follows, I first present a brief discussion of the literature on gendered bodies and technologies, particularly as they relate to menstruation and menstrual technologies. After introducing my data and methods, I turn to an examination of how menstruation was redefined in two key sites: the first is the creation and institutionalization of new scientific categories describing bleeding, and the second is the promotion of new frameworks for understanding bleeding through marketing websites directed at potential users. The first site shows how previously known distinctions related to bleeding were made newly salient as clinical categories. The second site, marketing websites, shows how changed definitions of bleeding were conveyed to women. I conclude by exploring how studying both the social and material construction of menstruation enhances our understanding of gendered embodiment. 


\section{Gendered Bodies, Technology, and Menstruation}

There is a rich body of feminist research on gender, bodies, and technologies. In this section, I bring together feminist literature on the social and material construction of gendered bodies with technology studies literature emphasizing how technologies, inscribed with gendered ideologies, are actively used in the performance of gender. Together, this work explains why promoters of menstrual suppression would seek to change beliefs that monthly menstruation is natural and necessary (Mamo and Fosket 2009). Past research has shown that when gender identities or behaviors inscribed in technologies do not match dominant gender norms, developers can attempt to change those norms (Oudshoorn 2003a). The introduction of menstrual suppression prompted not only a challenge to norms of gendered embodiment, but also a redefinition of menstruation itself.

Feminist studies of bodies and embodiment have provided key tools for this analysis by showing the ways in which gender norms and ideologies shape how individuals display and "do" gender using their bodies (Butler 1990; West and Zimmerman 1987); how sexed and gendered bodies are perceived (Friedman 2013); and the appearance, capacities, and biology of bodies themselves (Fausto-Sterling 2005; Young 1990). These scholars theorize the body as neither purely biological/natural nor purely cultural/ social, but rather as disrupting these boundaries (Fausto-Sterling 2005; Grosz 1994; Haraway 1991). Technologies, especially those (like medications) that change the body invisibly from within, make clear the simultaneously social and material construction of bodies and the dynamic nature of biology (Mamo and Fosket 2009; Roberts 2007). Recent feminist theories of materiality go even further, showing that bodies take shape and shift in relation to both the material conditions that surround them and the conceptual tools that shape our understanding of and interventions into biology (Frost 2014; Pitts-Taylor 2016; Roberts 2007; Wilson 2010).

Because menstruation is so closely associated with biological femaleness, technologies that change menstruation make visible the construction of gendered bodies and challenge the equation of gender and biological sex (Mamo and Fosket 2009). Menstruation has long served as a central aspect of essentialized, biological understandings of sex difference (at least since the nineteenth century) (Laqueur 1992; Martin [1987] 2001), serving as a marker of biological sex and thus a site of the production of gender on the body. Since the early twentieth century, the hormonal model of sex has dominated medical understandings of menstruation (Oudshoorn 1994). Under the hormonal model, monthly cycles define both female biology and sexual difference. "Unexamined assumptions that normal equals periodically regular" (Martin 1999, 104) meant that any disruption to or absence of regular cycles was considered a pathological deviation from the female norm and in need of medical intervention. Menopause has thus been considered doubly problematic, with medical literature equating the lack of menstrual cycles to both 
maleness and a breakdown of communication among bodily systems (Martin [1987] 2001; Roberts 2007).

One of the first uses of exogenous sex hormones for women was to correct menstrual irregularity (Oudshoorn 1994). Later, when oral contraceptives were first introduced, they were designed to include regular bleeding, a decision that most accounts explain was intended to make the pill more acceptable (to women, the church, and pharmaceutical executives) (Marks 2001; Watkins 1998). The idea that monthly bleeding would make oral contraceptives more acceptable depends on the medical and popular belief that regular menstrual cycles define "normal” women's bodies. By building an approximation of menstruation into hormonal contraceptives, developers simultaneously made birth control seem more natural and reinforced the idea that monthly periods should be the norm by physically producing them in women's bodies (Oudshoorn 1994).

Menstruation is just one of many examples that feminist scholars have drawn on to show how ideologies of gender work through technologies to shape bodies and subjectivities (Balsamo 1995; De Lauretis 1987; Mamo and Fosket 2009) and how individuals use technologies to perform gender (Oudshoorn and Pinch 2003b). "Technologies of gendered bodies" construct the body both materially and discursively to bring them in line with ideologies of gender (Balsamo 1995; Mamo and Fishman 2001). One way this happens is through the process of configuration, in which developers "configure" or "script" gendered users as they anticipate-and, ultimately, produce - the knowledge, identities, and behaviors ideal users will bring to their interactions with technologies (Akrich 1992; Oudshoorn and Pinch 2003a; Woolgar 1991). Gendered identities and behaviors can be inscribed in technologies in ways that "invite or inhibit specific performances of gender identities and relations," but users must enact these performances through active use; in doing so, they can accept, reject, or modify gendered scripts (Oudshoorn and Pinch 2003b, 10). Attention to technology is a necessary component of theorizing how individuals do gender and how bodies materialize sex/gender (Oudshoorn 2003b; Roberts 2007).

Users are more likely to take up gendered scripts if they align with dominant gender norms and culturally prevalent embodiments (Oudshoorn 2003b; Roberts 2007, 155). When new technologies challenge hegemonic gender identities, the configuration process may be used to shift gender norms (Oudshoorn 2003b). In the case of menstrual suppression birth control, transforming the body to eliminate menstruation challenges several aspects of dominant understandings of menstruation and women's bodies. Medical and popular understandings identify regular monthly bleeding as a defining feature of the menstrual cycle and of female bodies; normalizing menstrual suppression, therefore, meant shifting prominent beliefs about menstruation across multiple discourses.

One way to shift popular beliefs is through advertising campaigns. Advertisements for menstrual products significantly shaped popular discourse 
and understandings of menstruation across the twentieth century. Emerging scientific understandings of menstruation and new public discourses of the body coincided with the mass-production of disposable personal products and the advertising intended to popularize them (Freidenfelds 2009). Early ads for pads and tampons sought to instill in women new "modern" understandings of the body and menstruation, emphasizing hygienic practices and secrecy. They worked to persuade women that they did not need to restrict their activities during menstruation-particularly with the assistance of commercially produced menstrual products that would allow them to conceal evidence of menstruation (Freidenfelds 2009; Vostral 2008). Later advertisements emphasized freedom, empowerment, and continuous productivity (Vostral 2008). Other popular culture depictions have furthered ideas of menstruation as a source of shame and embarrassment, requiring vigilant self-surveillance to hide all signs of bleeding (Kissling 2006).

These cultural understandings and expectations of menstruation affect women's embodied experiences (Martin [1987] 2001). They are critical components of culturally prevalent embodiments, particular to a certain place and time (Lock 1993). As shown by Freidenfelds (2009), U.S. women's understandings and experiences of menstruation changed throughout the twentieth century as they embodied the shift to modernity through the use of new menstrual technologies. These products facilitated (and were required by) new norms of embodiment, although their use was taken up unevenly in ways that reflected and exacerbated stratification by class, race, and ethnicity. Menstrual technologies and the discourse of "the modern period" also initiated the "body project" of menstrual surveillance and management (Brumberg 1998; Freidenfelds 2009). As women increased their activity outside the home during menstruation amid prevailing norms insisting that bleeding be hidden, women became responsible for an increasing range of self-monitoring and body-management tasks. Stigma and secrecy meant that for many women menarche and menstruation were characterized by shame and embarrassment (Lee and Sasser-Coen 1996), even as the body project of managing menstruation could also provide a site of agency, pride, and resistance (Bobel 2010; Fingerson 2006).

While feminists hold a range of positions on menstruation and menstrual technology, a key focus of many feminist engagements has been valuing women's experiential ways of knowing and diminishing stigma (Aengst and Layne 2010; Bobel 2010). In addition to critiquing scientific representations of menstruation, feminist researchers have worked to generate new ones (Dan and Lewis 1992; Fausto-Sterling 2000; Martin 1991). Women's health activists have challenged regulatory stances on hormonal birth control and tampon regulation, innovated new ways of producing knowledge about women's bodies through self-help health, and developed new technologies of menstrual management such as menstrual extraction (Bobel 2010; Morgen 2002). Feminist challenges to dominant understandings of menstruation have 
emphasized valuing monthly menstruation as a sign of good health, challenging shame and secrecy, and highlighting how the profit-driven menstrual product industry risks women's health (Bobel 2010).

Despite their significant differences, feminist challenges share with mainstream medical and popular understandings the belief that regular, monthly bleeding defines healthy menstruation. The introduction of menstrual suppression birth control challenged this belief, which cyclic hormonal birth control had played a significant role in reproducing and reinforcing. By transforming the body to eliminate both visible and experienced signs of menstrual cycles, menstrual suppression challenges cyclicity as a defining feature of female bodies. If medical technologies must align with culturally prevalent embodiments (Roberts 2007) and gender norms and identities (Oudshoorn $2003 \mathrm{~b}$ ), how was menstrual suppression birth control introduced and promoted? I argue that definitions of menstruation were reworked across clinical, regulatory, and popular discourse. While the taken-for-granted naturalness of menstruation had allowed the periodic bleeding built into the Pill to naturalize hormonal contraception, the task of normalizing menstrual suppression required redefining menstruation to exclude some forms of bleeding. This explicit renegotiation of the definition of menstruation provides a clear view of the social construction of menstruation, as well as an opportunity to explore how its social construction matters to what menstruation is and its relation to gendered embodiment.

\section{Methods}

For this research, I analyzed two sets of texts through which new definitions of bleeding were institutionalized and disseminated. This analysis is situated in a larger project examining medical, advertising, and regulatory discourses surrounding menstrual suppression pills and practices more broadly, as well as how prescribers and women engage these technologies. In this article, I focus specifically on changing definitions of menstruation in regulatory discussions and advertising for menstrual suppression pills. The first part of this article demonstrates the creation and institutionalization of new clinical definitions of menstrual bleeding, drawing on two sources: transcripts from the January 23-24, 2007, meeting of the FDA's Reproductive Health Drug Advisory Committee, and two articles published in the January 2007 issue of the journal Contraception that discussed terminology and standards for measuring bleeding in clinical trials of combined hormonal contraceptives (CHCs) (Mishell et al. 2007a, 2007b). The second examines new definitions and terminology for menstruation used on websites promoting menstrual suppression.

First, I focused on a public meeting of the FDA's Reproductive Health Drugs Advisory Committee that convened to discuss the testing and approval of hormonal contraceptives. This meeting stands as the only public regulatory 
discussion of extended regimen birth control. The Advisory Committee convened to discuss clinical trial procedures and regulatory guidelines for the approval of new hormonal contraceptives, including issues pertaining specifically to extended regimen birth control. FDA advisory committee meetings are convened periodically to provide an additional level of review for the approval of new products, to evaluate safety data and reconsider previously approved drugs, or to address general questions about the drug approval process (as in this case) (Institute of Medicine et al. 1992; Leiter and White 2015). Advisory committees supplement the FDA's in-house expertise and provide additional scientific legitimacy to FDA decisions that are "too political" to be decided internally (Jasanoff 1994). The FDA determines in advance a specific set of questions the committee will address. At the January 2007 meeting, the committee was made up of 20 members, mainly academic physicians (primarily specialists in obstetrics/gynecology), statisticians, and epidemiologists, along with one representative each for consumers, patients, and the pharmaceutical industry. Eight FDA employees also participated in the meetings (but did not vote). The topics on the meeting agenda included clinical trial design issues, contraceptive efficacy and risk/benefit analysis, cycle control, extended-dosing regimens, and product labeling.

The meeting agenda, transcripts, and materials are available on the FDA website. ${ }^{4}$ I downloaded the meeting transcripts and coded and analyzed them using Atlas.ti. Through a recursive process of open coding, I identified categories and themes in the transcripts, such as defining bleeding, patient responsibility, physician counseling, and providing information. My analysis here focuses on definitions of menstruation and bleeding, which appeared primarily in discussions of "cycle control" (i.e., the ability of hormonal contraception to produce bleeding at scheduled times and not at other times) and how to define, measure, and analyze bleeding data in clinical trials.

In the agenda and questions posed to the advisory committee, the FDA specifically asked for guidance on new guidelines proposed by a group of clinical trial researchers for defining, measuring, and analyzing bleeding in clinical trials of hormonal contraceptives. For this reason, I have included in my analysis the two journal articles proposing these guidelines. Published in the January 2007 issue of Contraception, the articles examined bleeding definitions and measures used in previous clinical trials for CHCs and proposed guidelines for future trials (Mishell et al. 2007a, 2007b). I analyzed these articles with a particular focus on their discussion of why new guidelines were necessary, the importance of studying bleeding related to $\mathrm{CHCs}$, and their specific proposals for defining, measuring, and analyzing bleeding in clinical trials.

Second, to assess how definitions of menstruation were conveyed to potential users of menstrual suppression birth control, I analyzed websites promoting menstrual suppression pills and practices. As individuals increasingly turn to the Internet for health information, pharmaceutical companies have featured websites as a central component of their direct-to-consumer marketing 
(Ebeling 2011). These include websites that advertise specific products, as well as those that are part of "disease education campaigns" meant to raise awareness of particular diseases while "branding" their association with a particular medication (Dumit 2012). To examine the meanings circulated to users, I studied the websites of the available brands of menstrual suppression pills and those promoting the practice of menstrual suppression more generally. I draw here on analysis of five websites accessed in January and February of 2009. Three were websites for the brands of extended-cycle and continuous-use oral contraceptives available at that time: Seasonique, Seasonale, and Lybrel. The fourth was fewerperiods.com, an unbranded website promoting the use of hormonal contraceptives (of all kinds) to suppress menstruation. Although it did not promote any particular brand or product, the website was produced by DuraMed/Barr Laboratories, Inc., makers of Seasonale and Seasonique, and the company logo could be found at the bottom of the page. ${ }^{5}$ Finally, I included materials from the website of the Association of Reproductive Health Professionals, ${ }^{6}$ including the interactive tool, "Menstrual Suppression: What It Is, and How to Do It," and the fact sheet, "Health Matters: Understanding Menstrual Suppression." Both were developed using unrestricted grants from both Barr and Wyeth. ${ }^{7}$

These websites represent the web-based marketing for all of the available brands of menstrual suppression pills at the time of analysis, plus two prominent sites explicitly promoting the practice of menstrual suppression that purported to provide independent, authoritative, medically sanctioned information. While this analysis does not include all online discussions of menstrual suppression, it does provide a sample of sites that were highly visible and that were presented as authoritative information about menstrual suppression (vs. blogs or forums). In analyzing the text and images on the website, I examined how menstruation was portrayed, how the websites described what menstrual suppression birth control is and what it does, and how the websites constructed potential or ideal users of menstrual suppression birth control.

\section{Redefining Menstruation}

\section{Scientific Categories and Institutionalization}

In January 2007, members of the FDA's Reproductive Health Drug Advisory Committee met to discuss a range of issues affecting clinical trials, FDA approval, and postapproval follow-up for new hormonal contraceptives. ${ }^{8}$ Cycle control was one of seven main topics on the meeting agenda. Two points were provided to frame the discussion: (1) New birth control pills approved in recent years (including one under FDA review at the time of the meeting) were taken in an extended cycle that postponed bleeding and promised women fewer periods; however, users complained of frequent and unpredictable bleeding. (2) Changes in the hormonal makeup of contraceptives, 
especially lower doses of estrogen, made breakthrough bleeding more common. The FDA posed two questions related to cycle control. The first was how researchers should assess bleeding patterns and cycle control in clinical trials - specifically, whether the FDA should adopt in their clinical trial guidelines a recently published proposal for defining and measuring bleeding. The second question was whether the FDA ought to ensure that extended regimen pills actually produced fewer overall days of bleeding. To prepare the committee for discussing the first question, Dr. James Trussell, one of the authors, presented the research and proposed guidelines to his fellow committee members. Because they were at the center of the advisory committee's discussion, I analyze the proposed guidelines in detail before returning to the committee meeting.

The guidelines were developed at the 2005 Hormonal Contraceptives Trial Methodology Consensus Conference (Mishell et al. 2007a, 2007b). Consensus conferences such as this one are often convened to develop and agree on new diagnoses, assessments of medical technologies, or guidelines for clinical decision making (Fishman 2004). This particular conference was funded by an unrestricted educational grant from Duramed Pharmaceuticals, which was at that time in the midst of clinical trials for Seasonique, a follow-up product to Seasonale. Two articles, coauthored by several clinical trial researchers, were published to convey the results of the conference. Of the seven coauthors, six disclosed financial and other ties to Duramed and Wyeth, the two companies with menstrual suppression birth control pills on the market or under FDA review (Mishell et al. 2007a). ${ }^{9}$ These ties to Duramed and Wyeth suggest that, while the guidelines do not explicitly reference extended regimen pills, the authors were likely aware that their proposals could affect clinical trials and FDA review of menstrual suppression pills under review or in development.

The first of the two articles examined the methods of evaluating bleeding used in clinical trials of CHCs approved between 1975 and 2003 (Mishell et al. 2007a). Explaining that lower hormone doses in more recent contraceptives resulted in higher rates of breakthrough bleeding and spotting, the authors argued that physicians need better data on how CHCs affect bleeding patterns to inform their prescribing decisions and patient counseling. The information available to physicians and consumers is, in some ways, limited to the information requested and reviewed by the FDA in the process of approving a new drug. Therefore, changing the information requested by regulators would also change the data collected by clinical trials and the information available to prescribing physicians and consumers. The FDA reviews drugs based on criteria of safety and efficacy; because bleeding patterns had not previously been considered relevant, the FDA had not required companies to provide information on cycle control when applying for approval of a new hormonal contraceptive. The article showed that individual regulators had at times asked for and evaluated information on bleeding patterns according to 
their own interest and expertise, but that the amount and format of information included in the reviews varied widely — and thus so had the information available to physicians and consumers as they decided which hormonal contraceptives to use (Mishell et al. 2007a).

The authors' review of existing clinical trials focused on the lack of consistent measures for bleeding and the shortcomings of the most commonly used terminology. Previous clinical trials and New Drug Applications for CHCs varied widely in how they defined bleeding, how they collected information about it, and how they analyzed and reported their data. Despite overall inconsistency, the most commonly used bleeding categories were those defined by the "Belsey criteria," introduced by World Health Organization researchers in the 1980s. Half of the studies used the criteria in some form (Mishell et al. 2007a, 6). The Belsey criteria established two categories: "bleeding" and "spotting." Bleeding is defined as "any bloody vaginal discharge that requires the use of such protection as pads or tampons," and "spotting" as "any bloody vaginal discharge that is not sufficient to require protection" (Belsey, Machines, and d'Arcangues 1986, 255). The main distinction between these categories is the amount of bleeding, determined by whether menstrual products would be used to manage it.

The authors critiqued the Belsey criteria for not accounting for the timing of bleeding and not distinguishing between bleeding produced by the withdrawal of contraceptive hormones and menstruation occurring in the absence of exogenous hormones. For these reasons, the authors argued that the Belsey criteria were not well suited to describing bleeding in studies of $\mathrm{CHCs}$, despite their frequent use. They stated:

While valuable for providing definitions and global descriptions of bleeding patterns associated with various methods of contraception, these criteria are not . . - particularly useful for the reporting of cyclic bleeding in women using CHCs. ... [T] he unmodified criteria do not differentiate bleeding occurring during active hormone therapy from that occurring during placebo interval, making the determination of the incidence of unscheduled bleeding/spotting difficult. (Mishell et al. 2007a, 9)

To address these shortcomings, the authors put forth in a second article new guidelines for defining, measuring, and reporting bleeding patterns (Mishell et al. 2007b). They proposed that researchers track the timing of bleeding, particularly with respect to whether it occurs during "placebo intervals" or while taking active hormones. The new guidelines stressed that researchers concerned with bleeding patterns related to hormonal contraception must distinguish bleeding from menstruation, and provided new terminology for doing so:

The use of traditional terminology ("periods" or "menses") should be abandoned with regards to CHCs and replaced by the use of "scheduled bleeding" 
or "withdrawal bleeding." E.g., any bleeding or spotting that occurs during hormone-free intervals regardless of the duration of the regimen. "Scheduled bleeding" emphasizes to the woman that her bleeding with hormonal methods is not the same as menstruation. (Mishell et al. 2007b, 13)

The authors proposed replacing the "traditional terminology" of periods and menses with new terminology that "emphasizes to the woman" the differences between hormonally produced bleeding and menstruation. In accordance with pill developers' intentions, many pill users recognize the familiar experience of monthly bleeding as a period, regardless of its physiological differences from menstruation. In contrast, the proposed terminology emphasizes bleeding as a side effect of birth control hormones that is "not the same as menstruation." While the published recommendations are directed to clinical researchers, here the authors specifically focus on changing how women think about their bleeding patterns.

Since before the introduction of the first hormonal contraceptive, researchers had known the distinction between bleeding produced by the withdrawal of birth control hormones and menstruation in the absence of synthetic hormones (Marks 2001). Specifying in the proposed guidelines that the terminology would apply to regimens of any duration suggests that this distinction is particularly important in the context of extended regimen contraceptives. The introduction of birth control pills intended for menstrual suppression provided the conditions in which this distinction became newly salient, prompting efforts to convince researchers of its significance.

At this point, my analysis returns to the FDA, where these new guidelines and categories structured the advisory committee's discussion of cycle control. In setting the agenda for the advisory committee meeting, the FDA directly asked the committee to evaluate the proposed guidelines and make a recommendation about whether the FDA should adopt them. Following a presentation of the guidelines, the committee's discussion focused primarily on the proposed terminology. Many committee members concurred that new terminology would communicate to women that withdrawal bleeding is not menstruation. Committee chair Lockwood, for example, praised the recommended language for emphasizing the differences between bleeding on and off hormonal contraceptives, stating that the new vocabulary "moves away from mixing metaphors with both physiologic and pharmacological processes" (U.S. FDA transcript, January 24, 2007, 15-16). Committee member Johnson favored the new standards because "both physicians and patients need to know what we mean when we say bleeding and spotting" (U.S. FDA transcript, January 24, 2007, 15).

However, not everyone at the meeting agreed that the new language would be easier to understand. One senior FDA official asked the committee to revisit the question of how to convey cycle control information to consumers. Scott Monroe, acting director of the FDA Division of Reproductive and Urologic Products, asked whether moving away from familiar language for 
describing bleeding might cause more, rather than less, confusion for consumers. Specifically, he asked how to describe bleeding patterns produced by extended regimen pills:

When we think in terms of a traditional monthly cycle, it is fairly easy to conceptualize things [bleeding patterns]. . . . But then when you are talking about longer intervals . . . let's say it is an $84 / 7$ [extended regimen] or a continuous [regimen] . . . then you have to start doing all this mental sort of arithmetic if you are trying to go back and relate it to a more traditional pill. We wondered if . . . everybody can instantly do the mental mathematics . . . ? I don't think your average person thinks in terms of numbers of anticipated bleeding days over a year, the numbers of withdrawals, and so on. (U.S. FDA transcript, January 24, $2007,42-43)$

Monroe highlighted that shifting to the language of withdrawals or anticipated bleeding days, instead of "periods," might make it more difficult for women to understand and compare extended and traditional pill regimens and their effects on bleeding.

The advisory committee voted to approve the proposed guidelines. In doing so, they institutionalized new categories for different types of bleeding. Because FDA guidelines dictate the information that future clinical trials will collect, they can determine what information the FDA can provide to physicians and consumers. Adopting these guidelines meant that potential users would also need to adopt-or at least under-stand-these categories to make sense of the information available about hormonal contraceptives.

The proposal and discussion of new guidelines for measuring and evaluating bleeding demonstrates the work required to make the known distinction between menstruation and withdrawal bleeding salient for clinical researchers, regulators, and physicians. Further, the discussion of terminology highlights that both researchers and regulators were explicitly concerned with changing how women think about bleeding. Establishing and institutionalizing new terminology and clinical categories of bleeding facilitated the normalization of menstrual suppression by changing the object on which menstrual suppression birth control acts: not menstruation, but "scheduled" or "withdrawal" bleeding.

\section{Not a "Real" Period}

Prior to the initial consensus conference and ensuing FDA discussions, pharmaceutical advertising campaigns had already been working to change popular understandings of menstruation as they introduced menstrual suppression birth control (Mamo and Fosket 2009). On their websites and in print campaigns, the companies introduced potential users to menstrual suppression through images of an idealized lifestyle achievable with menstrual suppression and information that preempted questions about what is normal, natural, and 
safe. They presented detailed explanations of the menstrual cycle and introduced women to the "pill period"- a new term for the "scheduled" bleeding that occurs when women are taking cyclic hormonal birth control. In this section, I focus on these explanations of menstruation and the distinctions made between different kinds of periods. ${ }^{10}$ Although the websites continued to use the language of "periods," they stressed the same distinction between bleeding on and off the pill that was highlighted in the clinical guidelines. Promoting a new understanding of the experience of menstruation, this distinction brought attention to the ways that all hormonal birth control alters menstruation. In this way, pharmaceutical companies pioneered efforts to change how women understand menstruation that researchers and regulators took up later.

The language of "pill periods" is specifically tailored to the context of menstrual suppression; it is therefore important to examine closely how the websites construct these kinds of periods. The work of redefining menstruation figured prominently on the websites: all five devoted significant space to describing how the menstrual cycle works with and without the effects of hormonal birth control. The descriptions were structured around the distinction between bleeding on and off the pill, divided into three categories: the "regular" or "basic" menstrual cycle, the cycle when taking hormonal contraceptives, and the cycle when using hormonal birth control to suppress menstruation. ${ }^{11}$ See Figure 56.1 for a representative example from the Lybrel website.

As described in Figure 56.1, the "regular monthly period" occurs when hormones "naturally rise and fall." In contrast, the "traditional birth control period," or "pill period," results from the withdrawal of hormones during the placebo week. The new intermediary category of the "pill period" is built on the assumption of a fundamental difference between bleeding that occurs "naturally" and bleeding that occurs when taking hormonal contraceptives. The "pill period" is explained as a side effect of the pill itself. Finally, the website states that with Lybrel women "do not have regular menstrual periods or 'pill periods," because the pills provide continuous levels of hormones. Distinguishing between types of bleeding takes on new importance with the existence of menstrual suppression technology: "pill periods" are suppressed, not "regular periods." The purpose of introducing the "pill period," then, is to promote its suppression. As an intermediary between the "natural" menstrual cycle and menstrual suppression, the "pill period" normalizes menstrual suppression and repositions some forms of monthly bleeding as artificial, rather than natural.

The idea that women "do not have regular menstrual periods" seems relatively clear in the case of Lybrel, which is taken continuously to suppress both "regular" menstruation and "pill periods." However, the websites for Seasonale and Seasonique make similar claims, even though they are designed to produce four bleeding periods per year. How do these websites define menstruation in a way that distinguishes the periodic bleeding they produce 


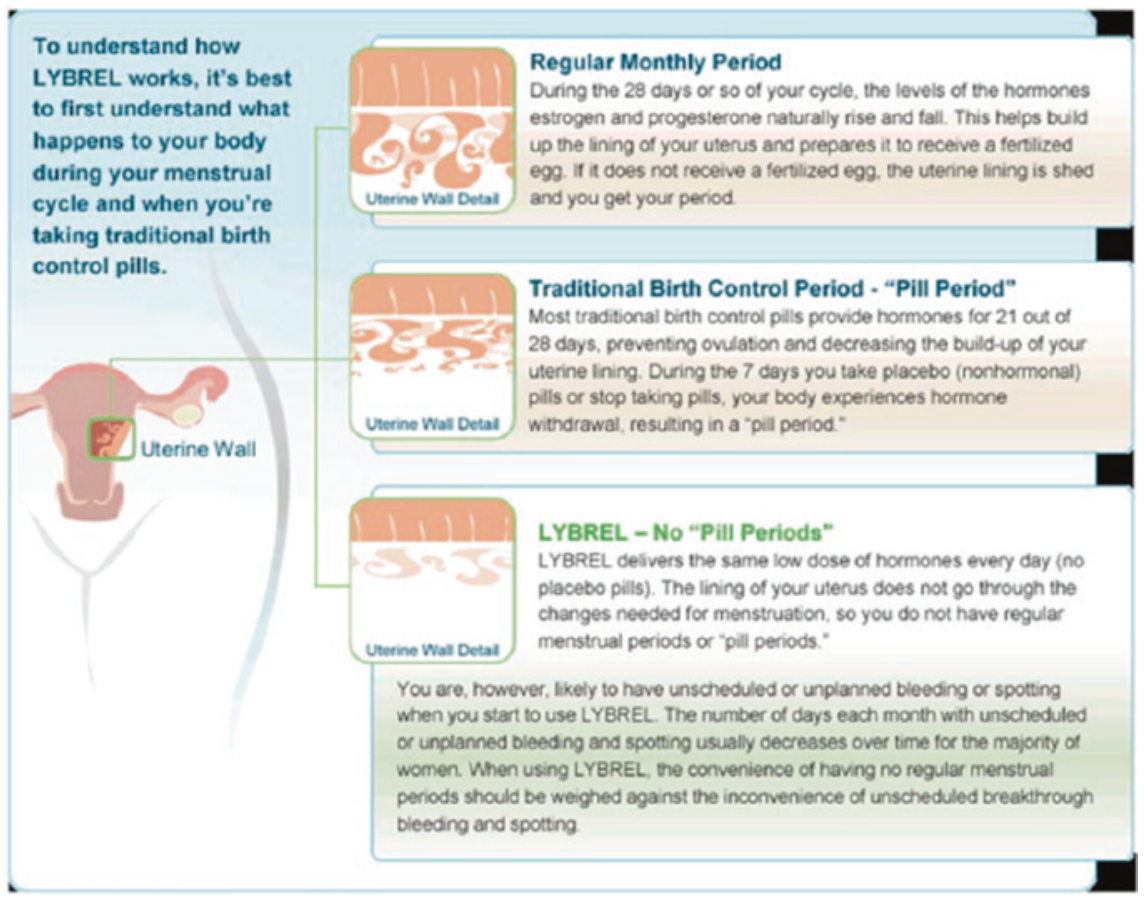

Fig. 56.1 "How Lybrel Works" from www.lybrel.com. (Source https://www.lybrel. com/works/. Credit: Wyeth Pharmaceuticals)

from "regular menstrual periods"? As seen in this quote from seasonique. com, one approach is to deemphasize menstruation as the key event of the menstrual cycle:

When you take a birth control pill, you don't have a menstrual cycle-your body doesn't prepare for pregnancy because you don't ovulate. As a result, your uterine lining doesn't build up, so there's no need to shed it. This is the reason you don't need to bleed every month when you take the Pill. ${ }^{12}$

To say that women taking birth control pills "don't have a menstrual cycle," the websites identify ovulation as the defining feature of the menstrual cycle. Because all hormonal birth control suppresses ovulation, by focusing on ovulation they suggest that all birth control pills are already suppressing the menstrual cycle. The fewerperiods.com website makes this point explicitly, stating that the "pill period" is "the reason having fewer periods is possible when you use hormonal birth control." In other words, all hormonal birth control pills suppress "real" periods, but "traditional" pills produce unnecessary bleeding as a side effect and disguise it as a "pill period." These statements assume that potential users already use hormonal birth control and will 
accept menstrual suppression once they learn that they are already suppressing their menstrual cycles and inducing a "fake" pill period.

In this way the websites work to revise-and perhaps even delegitimizewomen's knowledge and experiences of menstruation. The "Fewer Periods" website addresses how hormonal contraceptive users experience menstruation when it says, "The light, short bleeding that you experience on the Pill isn't a real menstrual period-it's actually a 'Pill period,' which is due to the withdrawal of hormones in your active pills." 13 Women taking hormonal birth control who experience regular monthly bleeding often understand that bleeding to be a menstrual period (as developers intended), and some might find this distinction irrelevant if the bodily sensations and effects are the same. Menstrual suppression websites encourage users to question this embodied experience of monthly bleeding, reinterpreting it as a "pill period." Redefining menstrual cycles around fluctuating hormone levels and ovulation shifts the defining event from something women feel and see-bleeding-to something (most) women experience less directly.

The "pill period" narrative revises existing knowledge about menstruation and provides a new interpretation for current and past experiences of bleeding. It encourages pill users to reinterpret all previous experiences of bleeding while on the pill, applying a new understanding that these were never "real periods." Like the clinical guidelines, the websites focus on changing how women think about menstruation, emphasizing that the bleeding that occurs when taking hormonal birth control is not actually menstruation, and thereby introducing new categories of bleeding. While this information is technically more accurate, it is important to ask why it appears only in conjunction with discussions of menstrual suppression.

\section{Menstruation as Multiple}

What work does this proliferation of bleeding categories do to undermine the seemingly obvious naturalness of menstruation? The revision of clinical, regulatory, and popular understandings of menstruation reversed the efforts of hormonal contraceptive developers, who built in regular monthly bleeding intending that it would be perceived as a period and that the assumed naturalness of menstruation would extend to birth control itself. To the extent that the experience of withdrawal bleeding has been considered a "period," normalizing menstrual suppression birth control necessitates denaturalizing bleeding by breaking the automatic association of monthly bleeding with "natural" menstruation. To redefine menstruation, researchers, regulators, and advertisers identified and highlighted certain material differences in bleeding - the presence or absence of "naturally" fluctuating hormones or ovulation, for example - to create new categories of bleeding.

Proliferating types of bleeding reveals as many and changeable what seemed to be a single natural phenomenon. Introducing the idea that many kinds of bleeding have been and continue to be misrecognized as 
menstruation made visible "the coexistence of multiple entities that go by the same name" (Mol 2002, 151). Menstruation was revealed as "multiple," "a single [bodily process] that in practice appears to be more than one- without being fragmented into many" (Mol 2002, 151). This multiplicity had been made coherent and stable through the socially meaningful experience of bleeding once per month and the taken-for-granted naturalness of menstruation. As Mol notes, when conflicting multiples of the body become apparent, "one reality wins" $(2002,55)$. Coherence could be (re) achieved by instituting hierarchy- "real" menstruation as defined by "natural" hormonal fluctuations was placed above the newer categories of "scheduled" or "withdrawal" bleeding and "pill periods," which would no longer be considered menstruation.

In this case, the proliferation of bleeding categories was re-hierarchized and used to narrow the definition of menstruation and support its suppression. However, there is opportunity for gender scholars in recognizing menstruation as multiple by taking seriously the material differences in bleeding that were mobilized to redefine menstruation. The hormone levels produced by hormonal contraceptives and the effects on the uterine lining of their abrupt withdrawal during a placebo week do differ from a menstrual cycle unaffected by external hormones. In what ways does it matter-and to whom - that withdrawal bleeding is different from menstruation? Examining "multiple" menstruation as revealed in this process of its redefinition allows feminist scholars to theorize how this particular "meeting of the conceptual and the biological has material effects" (Pitts-Taylor 2016, 42).

\section{Conclusion}

Cultural associations of menstruation with biological sex, nature, reproduction, and femininity make it an overdetermined site for the examination of gendered embodiment. Considering technologies that intervene in gendered bodies provides a vantage point from which to reconsider aspects of embodiment taken for granted as fixed, as they are socially and materially reconstructed. While we often take for granted what menstruation is, this case reveals coordinated effort across multiple realms to redefine menstruation by disaggregating the many types of bleeding that have been understood as menstruation.

This article has shown how categories of bleeding developed for use in clinical trials and institutionalized by the FDA aligned with online marketing campaigns for menstrual suppression by emphasizing the distinction between menstruation and withdrawal bleeding. This distinction challenges a longstanding equation of menstruation with both nature and biological sex that has been central to the relationship between birth control hormones and bleeding. Almost 50 years after the development of oral contraceptives, with the introduction of menstrual suppression birth control, pharmaceutical companies worked to undo the acceptance of all monthly bleeding as 
menstruation. They disclosed that oral contraceptives produced a "pill period" that was not a "real" period, and therefore unnecessary. Advertising campaigns promoted this new definition for reinterpreting the familiar experience of monthly bleeding. Scientists and regulators also took aim at the misrecognition as menstruation of multiple forms of bleeding. They proposed using the category of "scheduled" or "withdrawal" bleeding to distinguish it from menstruation.

The redefinition of menstruation undoubtedly provides another example of the social construction of the body and gender, and a further rejection of biological essentialism. The explicit re-negotiation of biological facts across a wide range of institutions-scientific research, medicine, pharmaceutical industry, federal regulators-offers further evidence that even the most irreducibly biological processes have been and continue to be subject to reinscription with new meanings. And yet, stopping here would again shy away from grappling with biology, with what is going on materially in the body. What response can feminist scholars and advocates give to the claim that "pill periods" are not "real" periods and are therefore unnecessary? Without theoretical tools to address material differences in bleeding, some may be left to call on something like a "natural" period and its importance to women's biology to critique or reject menstrual suppression.

In past encounters with these "interactions between the social and the biological that are not, or not only, linguistic or discursive" (Frost 2014, 316), feminist scholars have missed chances to analyze how "the meeting of the conceptual and the biological has material effects" (Pitts-Taylor 2016, 42). Feminist science studies scholars continue to argue that the dynamic multiplicity of biology undermines and explodes essentialist categories and biological determinism (Fausto-Sterling 2005; Frost 2014; Pitts-Taylor 2016; Roberts 2007; Wilson 2010). Taking seriously the material differences highlighted here in the process of redefining menstruation allows feminist scholars to theorize menstruation - and gendered embodiment-as multiple, highlighting the variation and dynamism of biology in its interactions with technology (Pitts-Taylor 2016).

The axiom of menstrual activism that "not all women menstruate, and not all menstruators are women" does not need to be taken as a rejection of biology and its relationship to gendered embodiment. It can be a call to investigate the interrelated social and material construction of menstruation and gender, exploring and highlighting "the capacity of biological substance to forge complex alliances and diverse forms" (Wilson 2010, 197). Complex arrangements of organs, tissues, hormones-produced in the body or taken in from outside-generate embodied experiences of regular, irregular, or absent bleeding. These occur in the context of gender binaries and cultural norms that demand management and concealment of bleeding, along with menstrual technologies that facilitate this. We can analyze these "complex alliances" that produce women that do or do not menstruate, menstruators who 
may or may not be women. Taking for granted what menstruation is and how it is defined obscures what can be learned by remaining open to menstruation's multiplicity and its relationship to gendered embodiment. Sociologists of gender and embodiment can enhance and strengthen our analysis by theoretically and empirically engaging the material aspects of biology as always in relation and interaction with their representations in specific social and historical contexts. ${ }^{14}$

\section{Notes}

1. "Not a Real Period?": Social and Material Constructions of Menstruation by Katie Ann Hasson was first published in 2016 in Gender or Society 30 (6): 958-983. Reprinted with permission. No further reproduction or distribution of the material is allowed without permission from the publisher.

2. Menstrual activists challenge this belief, pointing out that not all women menstruate and not all who menstruate are women, and use the term "menstruator" rather than women (Bobel 2010).

3. Menstrual extraction is a technique developed by feminist self-help health activists for removing the contents of the uterus at the (expected) start of a woman's period (Murphy 2012).

4. http://www.fda.gov/ohrms/dockets/ac/cder07.htm\#rhdac.

5. The fewerperiods.com website is now defunct and the URL redirects to seasonique.com. DuraMed Pharmaceuticals and its parent company, Barr Laboratories, have been acquired by Teva Women's Health, Inc.

6. ARHP was founded as "the education arm of Planned Parenthood Federation of America (PPFA) and incorporated as an independent organization in 1972" (http://www.arhp.org/about-us/about-arhp).

7. These websites were part of Duramed's advertising strategy for Seasonique (Saul 2007).

8. The discussion included oral contraceptives as well as transdermal and vaginal rings, but excluded injectable contraceptives (DepoProvera) and implants (Implanon, etc.).

9. The only author who did not report financial conflicts of interest was James Trussell. These connections do not necessarily indicate sinister intent. Clinical trial researchers are structurally positioned between drug developers, regulators, and prescribers (Fishman 2004). However, financial ties to pharmaceutical companies have been shown to affect study outcomes (Sismondo 2008).

10. Elsewhere I explore how depictions of menstrual suppression's ideal users and lifestyles convey classed and racialized meanings that reflect and reinforce stratified access to reproductive technologies.

11. In contrast, websites for cyclic birth control pills (e.g., Ortho TriCyclen Lo and LoEstrin) did not present detailed information about the menstrual cycle or discuss "pill periods" and how they differ from "regular" periods. Cyclic pills have little to gain from making a distinction between different kinds of periods.

12. http://seasonique.com/Consumer/BodyAndPeriod/FewerPeriodsPossible. aspx [emphasis added]. 
13. http://fewerperiods.com/FewerPeriodsPossible/Default.aspx.

14. I would like to thank Rene Almeling, Kate Darling, Dawn Dow, Hannah Landecker, Martine Lappe, Sarah Macdonald, Theresa MacPhail, Silvia Pasquetti, Leslie Salzinger, Jade Sasser, Rachel Washburn, Raka Ray and the members of her gender working group, and the USC Sociology Social Organization reading group for their feedback on earlier versions of this paper, with special thanks to Jo Reger and the anonymous reviewers from Gender \& Society for their generous comments. This work has also benefited from feedback provided after presentations to the Body and Embodiment Section at the 2013 ASA Annual Meeting and the Center for Feminist Research at USC.

\section{REFERENCES}

Aengst, Jennifer, and Linda Layne. 2010. The need to bleed? A feminist technology assessment of menstrual-suppressing birth control pills. In Feminist technology, edited by Linda L. Layne, Sharra L. Vostral, and Kate Boyer. Urbana: University of Illinois Press.

Akrich, Madeleine. 1992. The de-scription of technological objects. In Shaping technology/building society, edited by Wiebe E. Bijker and John Law. Cambridge, MA: MIT Press.

Association of Reproductive Health Professionals. 2006. Menstrual suppression: What it is and how to do it. http://www.arhp.org/Publications-and-Resources/ Patient-Resources/Interactive-Tools/menstrual-suppression.

Association of Reproductive Health Professionals. 2008. Health matters: Understanding menstrual suppression. http://www.arhp.org/Publications-and-Resources/PatientResources/fact-sheets/Understanding-Menstrual-Sup-pression.

Balsamo, Anne. 1995. Technologies of the gendered body: Reading cyborg women. Durham, NC: Duke University Press.

Belsey, Elizabeth M., David Machines, and Catherine d'Arcangues. 1986. The analysis of vaginal bleeding patterns induced by fertility regulating methods. Contraception 34 (3): 253-60.

Bobel, Chris. 2010. New blood: Third-wave feminism and the politics of menstruation. New Brunswick, NJ: Rutgers University Press.

Brumberg, Joan Jacobs. 1998. The body project: An intimate history of American girls. New York: Random House.

Buckley, Thomas C. T., and Alma Gottlieb. 1988. Blood magic: The anthropology of menstruation. Berkeley: University of California Press.

Butler, Judith. 1990. Gender trouble: Feminism and the subversion of identity. New York: Routledge.

Dan, Alice J., and Linda L. Lewis. 1992. Menstrual health in women's lives. Urbana: University of Illinois Press.

De Lauretis, Teresa. 1987. Technologies of gender: Essays on theory, film, and fiction. Bloomington: Indiana University Press.

Delaney, Janice, Mary Jane Lupton, and Emily Toth. 1988. The curse: A cultural history of menstruation. Urbana: University of Illinois Press.

Dumit, Joseph. 2012. Drugs for life: How pharmacentical companies define our health. Durham, NC: Duke University Press.

Ebeling, Mary. 2011. "Get with the program!": Pharmaceutical marketing, symptom checklists and self-diagnosis. Social Science \& Medicine 73 (6): 825-32. 
Fausto-Sterling, Anne. 2000. Sexing the body: Gender politics and the construction of sexuality. New York: Basic Books.

Fausto-Sterling, Anne. 2005. The bare bones of sex, Part 1: Sex and gender. Signs 30 (2): 1491-1527.

Fewer Periods. 2009. http://fewerperiods.com.

Fingerson, Laura. 2006. Girls in power: Gender, body, and menstruation in adolescence. Albany: State University of New York Press.

Fishman, Jennifer R. 2004. Manufacturing desire: The commodification of female sexual dysfunction. Social Studies of Science 34 (2): 187-218.

Freidenfelds, Lara. 2009. The modern period: Menstruation in twentieth-century America. Baltimore, MD: Johns Hopkins University Press.

Friedman, Asia. 2013. Blind to sameness: Sexpectations and the social construction of male and female bodies. Chicago: University of Chicago Press.

Frost, Samantha. 2014. Re-considering the turn to biology in feminist theory. Feminist Theory 15 (3): 307-26.

Grosz, Elizabeth A. 1994. Volatile bodies: Toward a corporeal feminism. Bloomington: Indiana University Press.

Haraway, Donna Jeanne. 1991. Simians, cyborgs, and women: The reinvention of nature. New York: Routledge.

Institute of Medicine, Richard A. Rettig, Laurence E. Earley, and Richard A. Merrill. 1992. Food and Drug Administration advisory committees. Washington, DC: National Academy Press.

Jasanoff, Sheila. 1994. The fifth branch: Science advisers as policymakers. Cambridge, MA: Harvard University Press.

Junod, Suzanne White, and Lara Marks. 2002. Women's trials: The approval of the first oral contraceptive pill in the United States and Great Britain. Journal of the History of Medicine and Allied Sciences 57 (2): 117-60.

Kissling, Elizabeth Arveda. 2006. Capitalizing on the curse: The business of menstruation. Boulder, CO: Lynne Rienner.

Laqueur, Thomas Walter. 1992. Making sex: Body and gender from the Greeks to Freud. Cambridge, MA: Harvard University Press.

Lee, Janet, and Jennifer Sasser-Coen. 1996. Blood stories: Menarche and the politics of the female body in contemporary U.S. Society. New York: Rout-ledge.

Leiter, Valerie, and Shelley K. White. 2015. Enmeshed in controversy: Claims about the risks of vaginal mesh devices. Health, Risk \& Society 17 (1): 64-80.

Lock, Margaret M. 1993. Encounters with aging: Mythologies of menopause in Japan and North America. Berkeley: University of California Press.

Luker, Kristin. 1984. Abortion and the politics of motherhood. Berkeley: University of California Press.

Lybrel. 2009. http://lybrel.com.

Mamo, Laura, and Jennifer R. Fishman. 2001. Potency in all the right places: Viagra as a technology of the gendered body. Body \& Society 7 (4): 13-35.

Mamo, Laura, and Jennifer Ruth Fosket. 2009. Scripting the body: Pharmaceuticals and the (re)making of menstruation. Signs: Journal of Women in Culture and Society 34 (4): 925-49.

Marks, Lara. 2001. Sexual chemistry: A history of the contraceptive pill. New Haven, CT: Yale University Press. 
Martin, Emily. 1991. The egg and the sperm: How science has constructed a romance based on stereotyped male and female roles. Signs: Journal of Women and Culture in Society 16:485-501.

Martin, Emily. 1999. The woman in the flexible body. In Revisioning women, bealth and healing: Feminist, cultural, and technoscience perspectives, edited by Adele Clarke and Virginia L. Olesen. New York: Routledge.

Martin, Emily. (1987) 2001. The woman in the body: A cultural analysis of reproduction. Boston: Beacon Press.

Mishell, Daniel R., John Guillebaud, Carolyn Westhoff, Anita L. Nelson, Andrew M. Kaunitz, James Trussell, and Ann Jeanette Davis. 2007a. Combined hormonal contraceptive trials: Variable data collection and bleeding assessment methodologies influence study outcomes and physician perception. Contraception 75 (1): 4-10.

Mishell, Daniel R., John Guillebaud, Carolyn Westhoff, Anita L. Nelson, Andrew M. Kaunitz, James Trussell, and Ann Jeanette Davis. 2007b. Recommendations for standardization of data collection and analysis of bleeding in combined hormone contraceptive trials. Contraception 75 (1): 11-15.

Mol, Annemarie. 2002. The body multiple: Ontology in medical practice. Durham, NC: Duke University Press.

Morgen, Sandra. 2002. Into our own hands: The women's health movement in the United States, 1969-1990. New Brunswick, NJ: Rutgers University Press.

Murphy, Michelle. 2012. Seizing the means of reproduction: Entanglements of feminism, health, and technoscience. Durham, NC: Duke University Press.

Oudshoorn, Nelly. 1994. Beyond the natural body: An archeology of sex hormones. London: Routledge.

Oudshoorn, Nelly. 2003a. Clinical trials as a cultural niche in which to configure the gender identities of users: The case of male contraceptive development. In How users matter: The co-construction of users and technologies, edited by Nelly Oudshoorn and T. J. Pinch. Cambridge: MIT Press.

Oudshoorn, Nelly. 2003b. The male pill: A biography of a technology in the making. Durham, NC: Duke University Press.

Oudshoorn, Nelly, and Trevor J. Pinch. 2003a. How users matter: The co-construction of users and technologies. Cambridge: MIT Press.

Oudshoorn, Nelly, and Trevor J. Pinch. 2003b. Introduction: How users and non-users matter. In How users matter: The co-construction of users and technologies, edited by Nelly Oudshoorn and T. J. Pinch. Cambridge: MIT Press.

Pitts-Taylor, Victoria. 2016. The brain's body: Neuroscience and corporeal politics. Durham, NC: Duke University Press.

Reagan, Leslie J. 1997. When abortion was a crime: Women, medicine, and law in the United States, 1867-1973. Berkeley: University of California Press.

Roberts, Celia. 2007. Messengers of sex: Hormones, biomedicine, and feminism. New York: Cambridge University Press.

Saul, Stephanie. 2007. Pill that eliminates the period gets mixed reviews. The New York Times, 20 April.

Seasonale. 2009. http://seasonale.com.

Seasonique. 2009. http://seasonique.com.

Sismondo, Sergio. 2008. How pharmaceutical industry funding affects trial outcomes: Causal structures and responses. Social Science \& Medicine 66 (9): 1909-14. 
United States Food and Drug Administration. 2007. Department of Health and Human Services, Food and Drug Administration, Center for Drug Evaluation and Research, Advisory Committee for Reproductive Health Drugs, Volume I (transcript). January 23.

United States Food and Drug Administration. 2007. Department of Health and Human Services, Food and Drug Administration, Center for Drug Evaluation and Research, Advisory Committee for Reproductive Health Drugs, Volume II (transcript). January 24 .

van de Walle, Etienne, and Elisha P. Renne. 2001. Regulating menstruation: Beliefs, practices, interpretations. Chicago: University of Chicago Press.

Vostral, Sharra L. 2008. Under wraps: A history of menstrual hygiene technology. Lanham, MD: Lexington Books.

Watkins, Elizabeth Siegel. 1998. On the pill: A social history of oral contraceptives, 1950-1970. Baltimore, MD: Johns Hopkins University Press.

Watkins, Elizabeth Siegel. 2012. How the pill became a lifestyle drug: The pharmaceutical industry and birth control in the United States since 1960. American Journal of Public Health 102 (8): 1462-72.

West, Candace, and Don H. Zimmerman. 1987. Doing gender. Gender \& Society 1 (2): 125-51.

Wilson, Elizabeth A. 2010. Underbelly. Differences 21 (1): 194-208.

Woolgar, Steve. 1991. Configuring the user: The case of usability trials. In A sociology of monsters: Essays on power, technology and domination, edited by John Law. New York: Routledge.

Young, Iris Marion. 1990. Throwing like a girl and other essays in feminist philosophy and social theory. Bloomington: Indiana University Press.

Open Access This chapter is licensed under the terms of the Creative Commons Attribution 4.0 International License (http://creativecommons.org/licenses/ by $/ 4.0 /$ ), which permits use, sharing, adaptation, distribution and reproduction in any medium or format, as long as you give appropriate credit to the original author(s) and the source, provide a link to the Creative Commons license and indicate if changes were made.

The images or other third party material in this chapter are included in the chapter's Creative Commons license, unless indicated otherwise in a credit line to the material. If material is not included in the chapter's Creative Commons license and your intended use is not permitted by statutory regulation or exceeds the permitted use, you will need to obtain permission directly from the copyright holder. 